\title{
New insights on the metabolism of ricinoleic acid in ruminants
}

\author{
Susana P. Alves, ${ }^{* 1}$ Cintia M. Araujo,† Rita C. Queiroga,‡ Marta S. Madruga,§ Michelle O. M. Parente,\# \\ Ariosvaldo N. Medeiros, $†$ and Rui J. B. Bessa* \\ ${ }^{*}$ Center for Interdisciplinary Research in Animal Health, Faculty of Veterinary Medicine, University of Lisbon, Av. da Universidade Técnica, \\ 1300-477 Lisbon, Portugal \\ †Department of Animal Science, Federal University of Paraiba, Areia-PB 58397-000, Brazil \\ ‡Department of Nutrition, and \\ §Department of Food Engineering, Technology Centre, Federal University of Paraiba, João Pessoa-PB 58051-900, Brazil \\ \#Center for Agrarian and Environmental Sciences, Federal University of Maranhão, Chapadinha-MA 65500-000, Brazil
}

\section{ABSTRACT}

Dairy goats were fed a total mixed ration with or without the inclusion of castor oil $[40 \mathrm{~g} / \mathrm{kg}$ of dry matter (DM)] to study the metabolism of ricinoleic acid (12-OH, cis-9-18:1). Ten goats, at $39.7 \pm 4.0 \mathrm{~d}$ in milk, were individually penned and allocated at random to the 2 experimental diets. Goats were manually milked twice a day. Milk fatty acids (FA) were analyzed as methyl esters and hydroxyl groups were derivatized in trimethylsilyl ethers. Apart from ricinoleic acid, 6 FA were only detected in the milk of the castor oil group. Ricinoleic acid composed $0.3 \%$ of total FA in milk of the castor oil group, whereas the hydroxy-FA (8-OH-14:0, 10-OH-16:0, and 12-OH-18:0) and oxoFA (8-oxo-14:0, 10-oxo-16:0, and 12-oxo-18:0) reached $7.5 \%$ of total FA in milk. We anticipate that these FA were derived from the metabolism of ricinoleic acid, although it was not clear if they were produced in the rumen or in the tissues. To confirm that, we conducted in vitro batch incubations repeated for 3 consecutive weeks with castor oil ( $40 \mathrm{~g} / \mathrm{kg}$ of DM) and strained rumen fluid from 2 fistulated sheep. To examine the products formed over time, incubation tubes were stopped at $0,6,12,24,48$, and $72 \mathrm{~h}$. The results of the in vitro experiment showed that ricinoleic acid was metabolized in the rumen at a slow rate and the main products formed were 12-OH-18:0 and 12-oxo-18:0, by hydrogenation of the cis-9 double bond, followed by oxidation of the hydroxyl group, respectively. Our results suggest that the 12-OH-18:0 and 12-oxo-18:0 escape rumen and are further metabolized through partial $\beta$-oxidation in ruminant tissues. We propose that the 10-OH-16:0 and 8-OH-14:0 found in goat milk of the castor oil group are successive products of the $\beta$-oxidation of $12-\mathrm{OH}-18: 0$, and the 10-oxo-16:0 and 8-oxo-14:0 are successive prod-

Received May 4, 2017.

Accepted July 3, 2017.

${ }^{1}$ Corresponding author: susanaalves@fmv.ulisboa.pt ucts of the 12-oxo-18:0 in tissues. Overall, our results indicate that ricinoleic acid is extensively metabolized in the rumen and tissues, producing mainly oxo- and hydroxy-FA that are further excreted in milk.

Key words: castor oil, ricinoleic acid, milk, rumen, fatty acid

\section{INTRODUCTION}

Castor oil plant (Ricinus communis L.) is one of the most important industrial crops in developing countries mostly due to its wide range of industrial uses. The castor oil, which is obtained by pressing the castor seeds, has unique characteristics including a high oxidative stability promoting longer shelf-life compared with other vegetable oils. Castor oil contains about 80 to 94\% of ricinoleic acid (Binder et al., 1962), a hydroxyunsaturated fatty acid (12-OH,cis-9-18:1), which gives the oil its distinct features. Ricinoleic acid is known to have antimicrobial properties (Novak et al., 1961); thus, it has been studied as a possible modulator of ruminal fermentation to be used as an alternative to ionophore additives to improve growth, feed intake, and efficiency. Indeed, inclusion of castor oil in diet of dairy cows (Gandra et al., 2014; de Jesus et al., 2016), bulls (Cruz et al., 2014; Silva et al., 2014), steers (Gandra et al., 2012), sheep (Maia et al., 2012a), or goat kids (Maia et al., 2012b) did not impair nutrient intake, digestibility, or growth performance.

Studies on the effects of dietary castor oil on the lipid composition of ruminant derived products are scarce. Prado et al. (2016) and Valero et al. (2014) reported that inclusion of a blend of castor oil and cashew nutshell liquid (Anacardium occidentale L.) in the diet of feedlot finishing bulls greatly affected the muscle fatty acid (FA) composition. However, in both studies the FA profile was limited and none of these studies identified the ricinoleic acid or other hydroxy-FA derivatives in muscle. Only Maia et al. (2012b) identified low quantities of ricinoleic acid in muscle of goat kids fed diets 
supplemented with $3 \%$ of castor oil. More scarce are the studies on the effects of castor oil on milk FA composition. It was reported that feeding $2 \mathrm{~g} / \mathrm{d}$ of ricinoleic acid to dairy cows increased milk yield and milk fat content (Gandra et al., 2014); in contrast, Pereira et al. (2010) found that inclusion of $3 \%$ of castor oil in goats diet reduced milk fat content and density compared with the control. However, neither study reported the milk FA composition. Only an older study found trace amounts of hydroxy-FA in milk fat of dairy cows fed a diet containing $0.5 \%$ of castor meal and castor oil (Robb et al., 1974), and in another study, only the ricinoleic acid was reported in cheese of goats fed diets containing 4\% castor oil (Medeiros et al., 2014).

Because castor oil contains about 80 to $90 \%$ of ricinoleic acid, we expect that it is metabolized in the rumen and tissues, and thus a large number of hydroxy-FA derivatives, together with minor amounts of ricinoleic acid, will be found in milk of ruminants fed castor oil. However, the metabolism of ricinoleic acid in the rumen or tissues has not been largely studied. In vitro experiments with rumen fluid and rumen bacteria were conducted to study the influence of ricinoleic acid on the metabolism of linoleic acid (Wallace et al., 2007; Ramos Morales et al., 2012). These studies were focused on the hypothesis that ricinoleic acid was an intermediate of CLA synthesis in the rumen, but no relevant attention was made to the hydroxy or other FA intermediates formed from ricinoleic acid. Hence, this work aims to study the effects of the inclusion of $40 \mathrm{~g}$ of castor oil $/ \mathrm{kg}$ of DM in the diet of dairy goats on the milk FA composition with particular emphasis on the potential FA intermediates derived from ricinoleic acid. In addition, we also aim to explore the possibility that the FA metabolites found in milk could result from the metabolism of ricinoleic acid in the rumen. To investigate this hypothesis, we incubated castor oil with ruminal digesta in vitro for 6 to $72 \mathrm{~h}$.

\section{MATERIALS AND METHODS}

\section{Animal Experiment and Diets}

Animal experiment was performed at the Field Station for Small Ruminant Research of the Federal University of Paraiba (João Pessoa, Brazil). Ten Saanen $\times$ Alpine goats, at $39.7 \pm 4.0 \mathrm{DIM}$ and weighing $46.8 \pm$ $6.1 \mathrm{~kg}$, were used. Goats were individually penned and allocated at random to 2 experimental diets: nonsupplemented (control) and supplemented with castor oil (40 $\mathrm{g} / \mathrm{kg}$ of DM). Feed was supplied as a TMR twice a day in excess $(20 \%)$ to ensure ad libitum intake and goats had continuous access to drinking water. Experimental diets (Table 1) were formulated according NRC (2007) to meet the nutritional requirements of goats producing $2 \mathrm{~kg}$ of milk daily with $3 \%$ fat. The experiment lasted $7 \mathrm{~d}$ with an adaptation period of $15 \mathrm{~d}$. Goats were manually milked twice a day. Before milking, the udder was cleaned and the strip-cup test was performed to detect mastitis. Post dipping was performed after milking using a commercial iodine solution. A composed milk sample per goat, representative of the last $2 \mathrm{~d}$ of the trial was prepared using proportional amounts of all milking samples. A composed sample per animal was collected using proportional amounts from morning and afternoon milking. Milk yield and DMI averaged $1.5 \pm 0.32 \mathrm{~kg} / \mathrm{d}$ and $1.5 \pm 0.17 \mathrm{~kg} / \mathrm{d}$, respectively.

\section{In Vitro Incubations}

In vitro batch incubations were conducted at Faculty of Veterinary Medicine, University of Lisbon (Portugal). Ruminal fluid was collected from 2 fistulated sheep before the morning meal and immediately transferred to the laboratory in a thermostatic box at $39^{\circ} \mathrm{C}$. Rumen fluid was immediately strained through 4 layers of cheesecloth and diluted $(1: 4, \mathrm{vol} / \mathrm{vol})$ in the medium of Goering and Van Soest (1970) under $\mathrm{CO}_{2}$ flux. The rumen buffered solution $(6 \mathrm{~mL})$ was distributed into Hungate tubes containing about $60 \mathrm{mg}$ of a commercial TMR and $2.5 \mathrm{mg}$ of castor oil (FJCampos, Pontinha, Portugal). The TMR contained dehydrated alfalfa (700 $\mathrm{g} / \mathrm{kg})$, wheat grain $(105 \mathrm{~g} / \mathrm{kg})$, soybean meal $(110 \mathrm{~g} /$ $\mathrm{kg})$, and minerals and premix $(25 \mathrm{~g} / \mathrm{kg})$. The chemical composition of the TMR was $902 \mathrm{~g} / \mathrm{kg}$ of DM, $175 \mathrm{~g}$ of $\mathrm{CP} / \mathrm{kg}$ of DM, $113 \mathrm{~g}$ of starch $/ \mathrm{kg}$ of DM, $81 \mathrm{~g}$ of ether extract/kg of DM, and $213 \mathrm{~g}$ of crude fiber $/ \mathrm{kg}$ of DM. For batch incubations, Hungate tubes were filled with $\mathrm{CO}_{2}$ and closed with a butyl rubber stopper and screw cap, then tubes were incubated in a water bath (Unitronic, J.P. Selecta, Barcelona, Spain) at $39^{\circ} \mathrm{C}$ with gentle agitation for $0,6,12,24,48$, and $72 \mathrm{~h}$. After incubation, tubes were directly frozen and stored at $-20^{\circ} \mathrm{C}$. The allocation of tubes to the treatments, incubation time, order of filling with buffered ruminal fluid, and position in the water bath were randomized. The incubation procedure was replicated 3 times in 3 consecutive weeks with 2 tubes per treatment and time. Samples were freeze-dried (ScanVac CoolSafe, LaboGene ApS, Lynge, Denmark) and stored at $-20^{\circ} \mathrm{C}$ until analysis.

\section{Fatty Acid and Dimethyl Acetal Analysis}

Fatty acid methyl esters were prepared from freezedried milk fat samples by direct transesterification using potassium hydroxide $(2 M)$ in methanol according to Rego et al. (2009). Fatty acid methyl esters and 
dimethyl acetals (DMA) from the in vitro batch incubations were prepared by a direct transesterification procedure using sodium methoxide $(0.5 \mathrm{M})$ in methanol followed by the addition of hydrogen chloride (1.25 $M$ ) in methanol according to Alves et al. (2013). The methyl nonadecanoate $(1 \mathrm{mg} / \mathrm{mL})$ was added as an internal standard. The hydroxyl groups of the FAME were derivatized in trimethylsilyl (TMS) ethers by reaction of the FAME extract with 10-fold excess by weight of N,O-Bis(trimethylsilyl)acetamide as silylating reagent in $1 \mathrm{~mL}$ of acetonitrile (Christie and Han, 2012). The mixture was left to react for about $30 \mathrm{~min}$ at room temperature and afterward it was dried in a stream of nitrogen. Samples were clean up by adding $4 \mathrm{~mL}$ of hexane and $1 \mathrm{~mL}$ of water. The hexane layer was dried over anhydrous sodium sulfate, decanted, and evaporated in a stream of nitrogen. Fatty acid methyl esters before and after silylation were analyzed by GLC with flame ionization detection using a Shimadzu GC 2010-Plus (Shimadzu, Kyoto, Japan) equipped with a SP-2560 (100 m $\times 0.25 \mathrm{~mm}, 0.20 \mu \mathrm{m}$ film thickness, Supelco, Bellefonte, PA) capillary column. The chromatographic conditions were as follows: injector and detector temperatures were set at 250 and $280^{\circ} \mathrm{C}$, respectively; helium was used as the carrier gas at 1 $\mathrm{mL} / \mathrm{min}$ constant flow; the initial oven temperature of $50^{\circ} \mathrm{C}$ was held for $1 \mathrm{~min}$, increased at $50^{\circ} \mathrm{C} / \mathrm{min}$ to $150^{\circ} \mathrm{C}$ and held for $20 \mathrm{~min}$, increased at $1^{\circ} \mathrm{C} / \mathrm{min}$ to $190^{\circ} \mathrm{C}$, and then increased at $2^{\circ} \mathrm{C} / \mathrm{min}$ to $220^{\circ} \mathrm{C}$ and held for $40 \mathrm{~min}$. Identification of FAME and DMA, as well as the position of the hydroxyl group, was achieved by analysis of the TMS derivatives by electron impact mass spectrometry using a Shimadzu GC-MS QP2010 Plus (Shimadzu) and according to published chromatograms (Alves et al., 2013). The chromatographic column and the GLC conditions were similar to the GC-flame ionization detector (FID) analysis. Additional mass spectrometer conditions were as follows: ion source temperature, $200^{\circ} \mathrm{C}$; interface temperature, $240^{\circ} \mathrm{C}$; and emission voltage, $70 \mathrm{eV}$. Fatty acids in milk fat samples were expressed as a percentage of total FA in the GC-FID chromatogram. Amounts of FA and DMA in incubation tubes were expressed as milligrams per flask and determined using the internal standard, assuming direct proportionality between GC-FID peak area and FA weight. Partial GC-MS chromatograms of the hydroxy-FAME and oxo-FAME regions are presented in Figures 1 and 2, respectively.

\section{Calculations and Statistical Analysis}

The milk fat melting point was estimated by computing the molar percentages of the milk FA and subsequently calculated the sum of the melting points

Table 1. Composition of the experimental diets and fatty acid composition of castor oil

\begin{tabular}{|c|c|c|c|c|}
\hline \multirow[b]{2}{*}{ Item } & \multicolumn{2}{|c|}{ Diet } & \multirow{2}{*}{$\begin{array}{c}\text { Castor oil } \\
\text { (in vivo) }\end{array}$} & \multirow{2}{*}{$\begin{array}{l}\text { Castor oil } \\
\text { (in vitro) }\end{array}$} \\
\hline & Control & Castor oil & & \\
\hline \multicolumn{5}{|l|}{ Ingredient $(\mathrm{g} / \mathrm{kg}$ of $\mathrm{DM})$} \\
\hline Corn meal & 304 & 259 & & \\
\hline Soybean meal & 165 & 170 & & \\
\hline Castor oil & 0 & 40 & & \\
\hline Vitamin/mineral supplement ${ }^{1}$ & 15 & 15 & & \\
\hline Elephant grass hay & 516 & 516 & & \\
\hline \multicolumn{5}{|l|}{ Chemical composition ( $\mathrm{g} / \mathrm{kg}$ of $\mathrm{DM})$} \\
\hline DM & 874 & 878 & & \\
\hline $\mathrm{CP}$ & 139 & 137 & & \\
\hline Ether extract & 26 & 63 & & \\
\hline $\mathrm{NDF}$ & 508 & 497 & & \\
\hline \multicolumn{5}{|c|}{ Fatty acid (g/100 g of total fatty acids) } \\
\hline $16: 0$ & 24.0 & 23.6 & 1.7 & 1.7 \\
\hline $18: 0$ & 4.9 & 4.8 & 1.3 & 1.7 \\
\hline cis-9-18:1 & 14.6 & 13.6 & 4.3 & 4.2 \\
\hline cis-11-18:1 & 0.9 & 0.9 & 0.6 & 0.7 \\
\hline $18: 2 \mathrm{n}-6$ & 37.3 & 35.4 & 7.2 & 6.4 \\
\hline 20:0 & 2.7 & 2.7 & 0.1 & 0.1 \\
\hline $20: 1$ & - & 0.04 & 0.9 & 0.6 \\
\hline $18: 3 n-3$ & 10.8 & 10.8 & 0.4 & 0.3 \\
\hline $22: 0$ & 1.9 & 1.9 & - & - \\
\hline 23:0 & 0.7 & 0.7 & - & - \\
\hline $24: 0$ & 2.3 & 2.3 & - & - \\
\hline 12-OH,cis-9-18:1 (ricinoleic acid) & - & 3.4 & 83.6 & 84.4 \\
\hline
\end{tabular}

${ }^{1}$ Composition per kilogram of DM: $180 \mathrm{~g}$ of Ca, $71 \mathrm{~g}$ of P, $28 \mathrm{~g}$ of K, $20 \mathrm{~g}$ of S, $20 \mathrm{~g}$ of $\mathrm{Mg}, 400 \mathrm{mg}$ of $\mathrm{Cu}, 30$ $\mathrm{mg}$ of Co, $10 \mathrm{mg}$ of Cr, $250 \mathrm{mg}$ of P, $150 \mathrm{mg}$ of I, 1,350 mg of Mn, $15 \mathrm{mg}$ of Se, 1,700 $\mathrm{mg}$ of Zn, $710 \mathrm{mg}$ of Fe, $135,000 \mathrm{IU}$ of vitamin $\mathrm{A}, 68,000 \mathrm{IU}$ of vitamin $\mathrm{D}_{3}$, and $450 \mathrm{mg}$ of vitamin $\mathrm{E}$. 


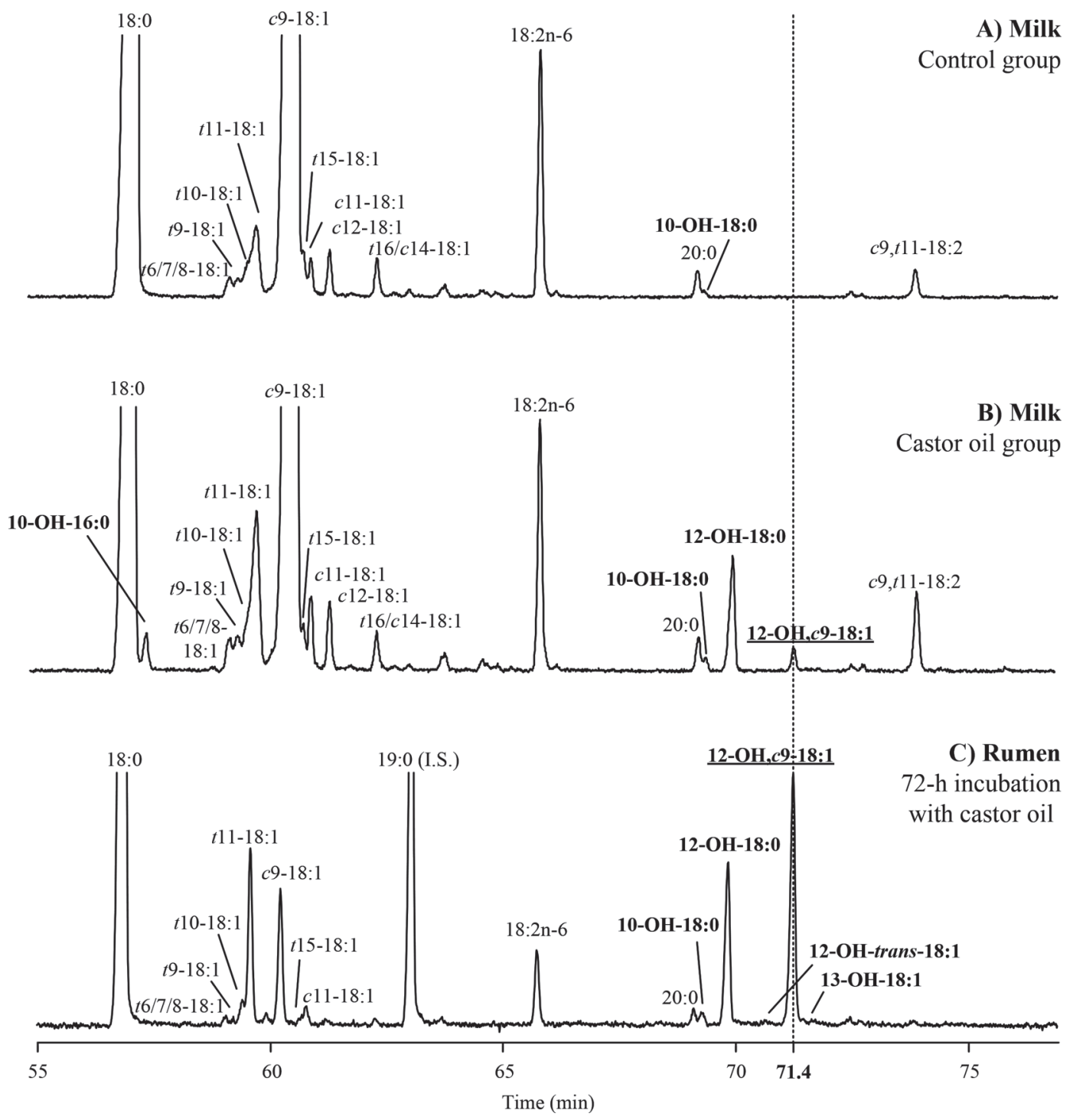

Figure 1. Partial GC-MS chromatogram from the region between 55 and $77 \mathrm{~min}$. (A) FAME + trimethylsilyl (TMS) derivatives from a milk fat sample of the control group; (B) FAME + TMS derivatives from a milk fat sample of the castor oil group; (C) FAME + TMS derivatives from 72-h incubations of castor oil with strained rumen fluid. $c=c i s ; t=$ trans. I.S. $=$ internal standard.

weighted by the respective FA molar percentages as described in Toral et al. (2013).

The proportionate disappearance of the biohydrogenation substrates (BS), 12-OH, cis-9-18:1, 18:2n-6, and 18:3n-3, during $6,12,24,48$, and $72 \mathrm{~h}$ of incubation was calculated as follows:

$$
\text { disappearance }(\%)=\left[\left(\mathrm{BS}_{0}-\mathrm{BS}_{\mathrm{t}}\right) / \mathrm{BS}_{0}\right] \times 100,
$$

where BS is $12-\mathrm{OH}$, cis-9-18:1, $18: 2 \mathrm{n}-6$, or $18: 3 \mathrm{n}-3$ expressed in milligrams per milligram of total $\mathrm{C} 18 \mathrm{FA}$ in tubes at time $0\left(\mathrm{BS}_{0}\right)$ and time $\mathrm{t}\left(\mathrm{BS}_{\mathrm{t}} ; \mathrm{t}=6,12,24\right.$, 48 , or $72 \mathrm{~h}$ ).
Milk FA composition was analyzed using the MIXED procedure of SAS 9.0 (SAS Institute Inc., Cary, NC) with a model that included the treatment (control vs. castor oil) as the single fixed effect. When needed, the group option of the repeated statement was included in the model to accommodate the variance heterogeneity. In vitro data were analyzed using the MIXED procedure of SAS considering the weekly runs as random block and the incubation time as a categorical fixed effect. The linear, quadratic, and cubic effects of incubation time were evaluated using the respective polynomial orthogonal contrasts after computing the contrast coefficients with the Proc IML of SAS. Least squares means 


\section{A) Milk}

Control group

20:4n-6 10-0x0-18:0

\section{B) Milk}

Castor oil group

12-0xo-18:0
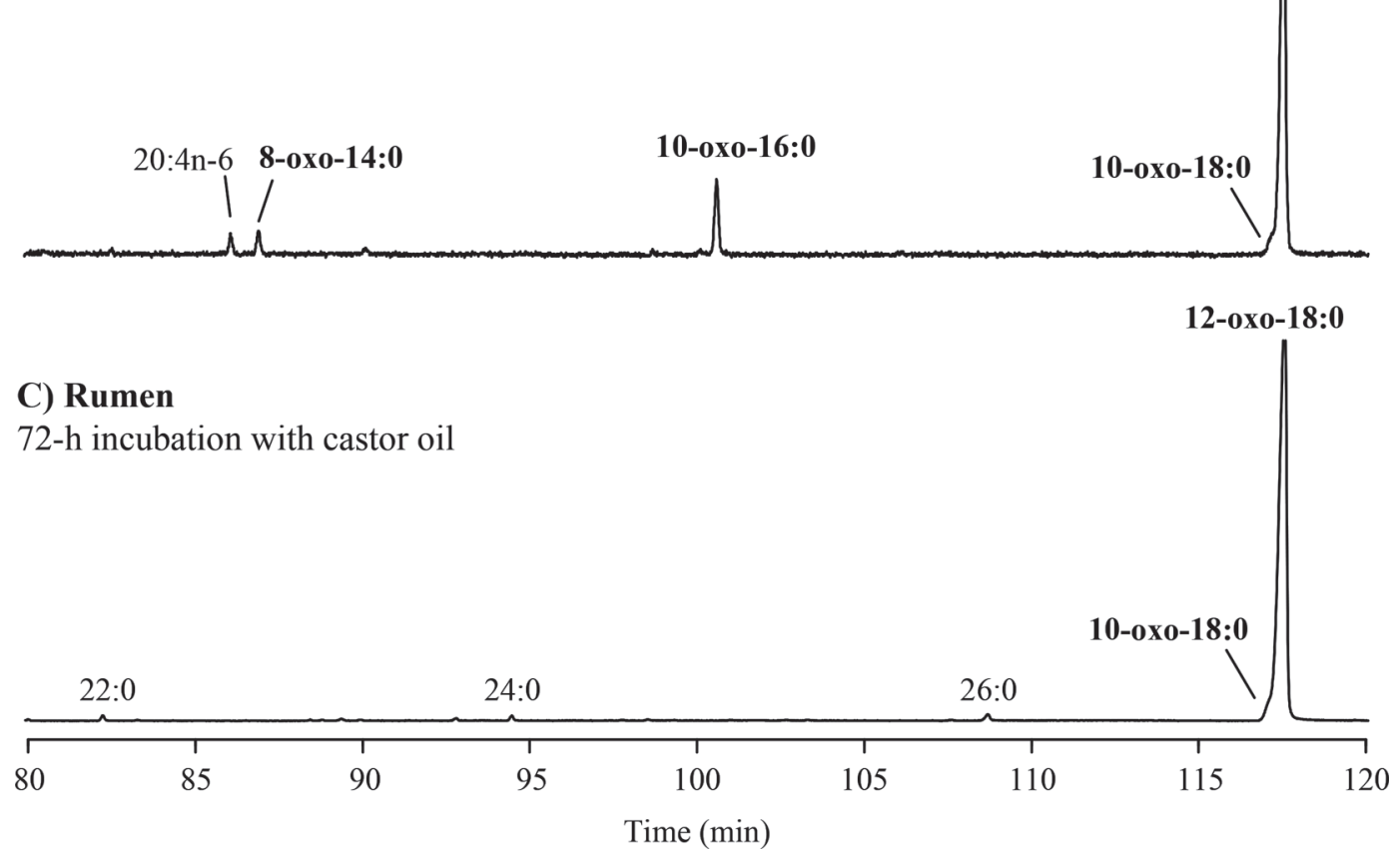

Figure 2. Partial GC-MS chromatogram from the region between 80 and 120 min. (A) FAME + trimethylsilyl (TMS) derivatives of a milk fat sample from the control group; (B) FAME + TMS derivatives of a milk fat sample from the castor oil group; (C) FAME + TMS derivatives from 72 -h incubations of castor oil with strained rumen fluid.

and standard error of the mean are reported, and treatment or contrast effects were considered significant at $P<0.05$ and trends toward significance at $P=0.05$ to 0.10 .

\section{RESULTS}

\section{Fatty Acid Composition of Milk}

Milk FA composition of goats fed a control diet or with the inclusion of castor oil is presented in Table 2. As expected, we detected the ricinoleic acid (12-OH, cis-9-18:1) in milk of the castor oil group, reaching about $0.3 \%$ of total $\mathrm{FA}$. We also detected and identified in milk fat of the castor oil group several
hydroxy-FA (i.e., 8-OH-14:0, 10-OH-16:0, and 12-OH18:0) and oxo-FA (i.e., 8-oxo-14:0, 10-oxo-16:0, and 12-oxo-18:0), which were not detected in the control group. These hydroxy- and oxo-FA composed about $8 \%$ of total FA in the castor oil group. Additionally, the 10-OH-18:0 and 10-oxo-18:0 were identified in both groups; however, both proportions were higher $(P=$ 0.012 and $P=0.035$, respectively) in milk fat of the castor oil group compared with the control.

Nevertheless, the most abundant FA in milk were the cis-9-18:1, 16:0, and 18:0, which proportions averaged about 26,21 , and $18 \%$ of total FA, respectively. Both cis-9-18:1 and 18:0 proportions tended $(P=0.058$ and $P=0.064$, respectively) to decrease with the incorporation of castor oil in diet, whereas 16:0 was not af- 
fected $(P=0.607)$. Moreover, castor oil incorporation decreased $(P<0.05)$ the proportions of 4:0, cis-9-14:1, trans-5-18:1, trans-16-18:1, and 18:2n-6 in milk. On the contrary, the proportions of $15: 0$, cis-7-16:1, cis11-18:1, 20:1 were higher $(P<0.05)$ in milk of the castor oil group compared with control; however, these FA only represented $1.6 \%$ of total FA in milk. Regarding the partial sums, the proportions of total SFA was lower $(P=0.009)$ and cis-MUFA tended $(P=0.075)$ to be lower in the castor oil group compared with the control. In addition, we observed a difference $(P=0.003)$ for the estimated milk melting points, being $38.7^{\circ} \mathrm{C}$ for the control group and $41.4^{\circ} \mathrm{C}$ for the castor oil group.

\section{In Vitro Batch Incubations}

Incubation of castor oil with strained ruminal fluid for 6 to $72 \mathrm{~h}$ resulted in extensive metabolization of ricinoleic acid (Figure 3A), showing a linear and quadratic decreased $(P<0.05)$ from $1.7 \mathrm{mg}$ at $0 \mathrm{~h}$ to $0.2 \mathrm{mg}$ at $72 \mathrm{~h}$ (Table 3 ). Figure $3 \mathrm{~A}$ also shows the main intermediates formed at the end of $72 \mathrm{~h}$ of incubation. The 12-oxo-18:0 linear and quadratic increased $(P<0.05)$ with time, reaching $1.4 \mathrm{mg}$ per tube at 72 $\mathrm{h}$, and the 12-OH-18:0 showed linear, quadratic, and cubic responses $(P<0.05)$ to incubation time (Table 3), reaching $0.4 \mathrm{mg}$ per tube at $72 \mathrm{~h}$. Figure $3 \mathrm{~B}$ shows the kinetic curves of the other oxo- and hydroxy-FA that were also produced during $72 \mathrm{~h}$ of incubation with castor oil. We verified linear, quadratic, and cubic responses $(P<0.05)$ for the 10-OH-18:0, 13-OH-18:0, and $13-\mathrm{OH}-18: 1$, quadratic and cubic responses for 12 $\mathrm{OH}-18: 1$, and both 13-OH-18:1 and 10-oxo-18:0 showed linear and quadratic responses $(P<0.05)$ with incubation time (Table 3).

The 18:2n-6 was also metabolized during in vitro incubation with castor oil (Figure 3C), decreasing from $800 \mu \mathrm{g}$ at $0 \mathrm{~h}$ to $60 \mu \mathrm{g}$ per tube at $72 \mathrm{~h}$, under a kinetic curve with a linear, quadratic, and cubic response (Table 3). Figure 3C shows that only minor amounts of cis-9,trans-11-18:2 were detected in incubation tubes; however, it linearly and quadratically decreased from $11.2 \mu \mathrm{g}$ at $0 \mathrm{~h}$ to $4.6 \mu \mathrm{g}$ at $72 \mathrm{~h}$ of incubation. On the contrary, at the first $6 \mathrm{~h}$ a large amount of trans-18:1 isomers, particular trans-11, were formed (Figure 3C). Following this pattern, all the trans-18:1 isomers showed linear, quadratic, and cubic $(P<0.05)$ responses with time. Regarding the cis-9-18:1 and 18:3n-3, which are also known substrates for ruminal biohydrogenation, both decreased with incubation time (LQC contrasts, $P<0.05$ ), and on the contrary the production of 18:0 increased (LQC contrasts, $P<0.05$ ) reaching $1.9 \mathrm{mg}$ at $72 \mathrm{~h}$.
Figure 3D shows that incubation of castor oil with strained ruminal fluid for $72 \mathrm{~h}$ increased the amount of total FA and DMA in tubes (total FA+DMA). Compared with the branched-chain fatty acids (BCFA), the amount of DMA showed a rapid increase in the first 12 $\mathrm{h}$ of incubation followed by a slower decrease, whereas the BCFA showed a moderate increase (Q contrast, $P$ $<0.05)$ during the $72 \mathrm{~h}$ of incubation. The majority of DMA followed the same pattern, presenting the highest amount at $12 \mathrm{~h}$ of incubation (Table 4), but the DMA iso-14:0, 14:0, 16:0, trans-11-18:1, and cis-9-18:1 showed linear, quadratic, and cubic responses; the DMA iso-15:0 showed linear and quadratic response; and the DMA 15:0 showed only linear response to incubation time. Regarding the effect of incubation time on the BCFA composition (Table 4), the iso-14:0, iso-17:0, and anteiso-17:0 linear and quadratic responses increased with incubation time, whereas iso-15:0, anteiso-15:0, and iso-16:0 linear, quadratic, and cubic responses increased with time. Table 4 also presents the effect of incubation time on other minor SFA during in vitro batch incubation with castor oil.

\section{DISCUSSION}

Several studies reported that the incorporation of castor oil in diet of ruminants (Gandra et al., 2012, 2014; Maia et al., 2012a,b; Cruz et al., 2014) did not affect nutrient intake, digestibility, or growth performance. However, the effect of the incorporation of castor oil in the FA composition of milk, particularly the specific FA resultant from the metabolism of ricinoleic acid, has not been studied. We hypothesized that ricinoleic acid, which in our experiment composed $84 \%$ of total FA in castor oil, is intensively metabolized in the rumen and tissues and that a large number of hydroxy-FA metabolites will be found in milk fat. Thus, we conducted a detailed FA analysis of milk fat from goats fed a TMR with or without incorporation of $40 \mathrm{~g}$ of castor oil $/ \mathrm{kg}$ of DM, with particular emphasis on hydroxy-FA and its derivatives.

Our approach was to prepare FAME from milk fat samples and run on a cyanopropyl siloxane GLC capillary column currently recommended for the analysis of FAME from complex mixtures. This column allows the separation of most of the trans-18:1 isomers as well as the comparison with the FAME profile of the majority of the studies regarding ruminant milk fat. However, because the highly polar characteristics of this column did not allow detecting hydroxy-FAME, we derivatized the hydroxyl groups in TMS ether derivatives, which are for long being used for the analysis of hydroxycontaining compounds (Eglinton et al., 1968). Thus, 
ALVES ET AL.

Table 2. Effect of castor oil on milk fatty acid composition (g/100 g of total fatty acids) and between milk fat melting point of goats

\begin{tabular}{|c|c|c|c|c|}
\hline \multirow[b]{2}{*}{ Item } & \multicolumn{2}{|c|}{ Treatment $^{1}$} & \multirow[b]{2}{*}{ SEM } & \multirow[b]{2}{*}{$P$-value } \\
\hline & Control & Castor oil & & \\
\hline $4: 0$ & 1.71 & 1.40 & 0.074 & 0.018 \\
\hline $6: 0$ & 1.77 & 1.55 & 0.122 & 0.241 \\
\hline $7: 0$ & 0.02 & 0.03 & 0.005 & 0.073 \\
\hline $8: 0$ & 1.90 & 1.73 & 0.182 & 0.533 \\
\hline 9:0 & 0.04 & 0.06 & 0.008 & 0.052 \\
\hline $10: 0$ & 5.75 & 5.43 & 0.603 & 0.716 \\
\hline 11:0 & 0.15 & 0.15 & 0.023 & 0.952 \\
\hline $12: 0$ & 2.17 & 2.08 & 0.181 & 0.728 \\
\hline iso-13:0 & 0.02 & 0.02 & 0.003 & 0.667 \\
\hline $13: 0$ & 0.09 & 0.08 & 0.011 & 0.717 \\
\hline iso-14:0 & 0.11 & 0.11 & 0.009 & 1.000 \\
\hline $14: 0$ & 6.72 & 6.34 & 0.209 & 0.236 \\
\hline cis-9-14:1 & 0.06 & 0.04 & 0.005 & 0.033 \\
\hline iso- $15: 0$ & 0.22 & 0.28 & 0.020 & 0.080 \\
\hline anteiso-15:0 & 0.38 & 0.41 & 0.016 & 0.165 \\
\hline $15: 0$ & 0.68 & 0.80 & 0.033 & 0.029 \\
\hline iso-16:0 & 0.27 & 0.25 & 0.028 & 0.700 \\
\hline $16: 0$ & 20.9 & 20.6 & 0.45 & 0.607 \\
\hline trans-9-16:1 & 0.06 & 0.06 & 0.012 & 0.825 \\
\hline cis-7-16:1 & 0.27 & 0.38 & 0.017 & 0.002 \\
\hline cis-9-16:1 & 0.36 & 0.38 & 0.021 & 0.449 \\
\hline iso- $17: 0$ & 0.36 & 0.41 & 0.024 & 0.171 \\
\hline anteiso-17:0 & 0.35 & 0.34 & 0.009 & 0.295 \\
\hline $17: 0$ & 0.42 & 0.46 & 0.018 & 0.153 \\
\hline cis-9-17:1 & 0.13 & 0.14 & 0.012 & 0.648 \\
\hline iso- $18: 0$ & 0.05 & 0.04 & 0.008 & 0.735 \\
\hline $18: 0$ & 19.3 & 16.0 & 1.09 & 0.064 \\
\hline trans-4-18:1 & 0.02 & 0.02 & 0.003 & 0.347 \\
\hline trans $-5-18: 1$ & 0.02 & 0.01 & 0.002 & 0.035 \\
\hline trans- $6 / 7 / 8$ 18:1 & 0.36 & 0.35 & 0.043 & 0.950 \\
\hline trans-9-18:1 & 0.31 & 0.35 & 0.036 & 0.410 \\
\hline trans-10-18:1 & 0.49 & 0.43 & 0.060 & 0.499 \\
\hline trans-11-18:1 & 1.18 & 1.64 & 0.205 & 0.151 \\
\hline trans-12-18:1 & 0.45 & 0.44 & 0.046 & 0.858 \\
\hline trans-15-18:1 & 0.20 & 0.16 & 0.018 & 0.169 \\
\hline trans-16-18:1 $1^{2}$ & 0.31 & 0.24 & 0.019 & 0.027 \\
\hline cis-9-18:1 & 27.6 & 24.3 & 1.08 & 0.058 \\
\hline cis-11-18:1 & 0.27 & 0.39 & 0.022 & 0.004 \\
\hline cis-12-18:1 & 0.25 & 0.25 & 0.043 & 0.925 \\
\hline cis-13-18:1 & 0.01 & 0.02 & 0.004 & 0.182 \\
\hline cis-15-18:1 & 0.02 & 0.01 & 0.005 & 0.332 \\
\hline $18: 2 \mathrm{n}-6$ & 2.02 & 1.59 & 0.092 & 0.011 \\
\hline Other-18:2 & 0.35 & 0.30 & 0.031 & 0.249 \\
\hline cis- 9, trans $-11-18: 2^{3}$ & 0.60 & 0.79 & 0.093 & 0.195 \\
\hline $18: 3 \mathrm{n}-6$ & 0.02 & 0.02 & 0.002 & 0.545 \\
\hline $18: 3 n-3$ & 0.08 & 0.08 & 0.004 & 0.740 \\
\hline $20: 0$ & 0.37 & 0.37 & 0.014 & 0.769 \\
\hline $20: 1$ & 0.05 & 0.07 & 0.002 & $<0.001$ \\
\hline$\Delta 5,8,11-20: 3$ & 0.05 & 0.05 & 0.007 & 1.000 \\
\hline $20: 3 n-6$ & 0.02 & 0.01 & 0.004 & 0.105 \\
\hline $20: 4 n-6$ & 0.15 & 0.17 & 0.009 & 0.265 \\
\hline $21: 0$ & 0.03 & 0.03 & 0.002 & 0.094 \\
\hline $22: 0$ & 0.07 & 0.06 & 0.006 & 0.296 \\
\hline $23: 0$ & 0.01 & 0.01 & 0.003 & 1.000 \\
\hline $24: 0$ & 0.02 & 0.04 & 0.012 & 0.265 \\
\hline 10-охо- $18: 0$ & 0.17 & 0.30 & 0.037 & 0.035 \\
\hline 10-OH-18:0 & 0.08 & 0.15 & 0.015 & 0.012 \\
\hline 8-oxo-14:0 & $\mathrm{ND}^{4}$ & 0.24 & 0.018 & - \\
\hline 10-oxo-16:0 & ND & 0.84 & 0.046 & - \\
\hline 12-oxo-18:0 & ND & 4.93 & 0.116 & - \\
\hline 8-OH-14:0 & ND & 0.12 & 0.004 & - \\
\hline 10-OH-16:0 & ND & 0.22 & 0.010 & - \\
\hline $12-\mathrm{OH}-18: 0$ & ND & 1.11 & 0.069 & - \\
\hline 12-OH, cis-9-18:1 & ND & 0.26 & 0.020 & - \\
\hline
\end{tabular}


Table 2 (Continued). Effect of castor oil on milk fatty acid composition (g/100 g of total fatty acids) and between milk fat melting point of goats

\begin{tabular}{|c|c|c|c|c|}
\hline \multirow[b]{2}{*}{ Item } & \multicolumn{2}{|c|}{ Treatment $^{1}$} & \multirow[b]{2}{*}{ SEM } & \multirow[b]{2}{*}{$P$-value } \\
\hline & Control & Castor oil & & \\
\hline Other fatty acids & 0.12 & 0.11 & 0.011 & 0.799 \\
\hline \multicolumn{5}{|l|}{ Partial sum } \\
\hline $\mathrm{SCFA}^{5}$ & 13.5 & 12.4 & 1.10 & 0.515 \\
\hline $\mathrm{BCFA}^{6}$ & 1.75 & 1.86 & 0.070 & 0.326 \\
\hline $\mathrm{SFA}^{7}$ & 48.6 & 44.8 & 0.80 & 0.009 \\
\hline cis-MUFA & 29.1 & 26.0 & 1.08 & 0.075 \\
\hline trans-MUFA & 3.40 & 3.71 & 0.418 & 0.621 \\
\hline PUFA & 3.29 & 3.00 & 0.171 & 0.272 \\
\hline Total $\mathrm{OH}$ and oxo & 0.25 & 8.18 & 0.084 & $<0.001$ \\
\hline Melting point ${ }^{8}$ & 38.7 & 41.4 & 0.45 & 0.003 \\
\hline
\end{tabular}

${ }^{1}$ Treatments: control $=$ TMR; castor oil $=$ TMR plus $40 \mathrm{~g}$ of castor oil $/ \mathrm{kg}$ of DM.

${ }^{2}$ Contains cis-14-18:1 as minor component.

${ }^{3}$ Contains trans-7, cis-9-18:2 and trans-8,cis-10-18:2 as minor components.

${ }^{4} \mathrm{ND}=$ not detected.

${ }^{5}$ Short-chain fatty acids, includes $\leq 12$-carbon fatty acids.

${ }^{6}$ Branched-chain fatty acids, includes all iso- and anteiso-fatty acids.

${ }^{7}$ Includes linear SFA of $\geq 13$-carbon chain length.

${ }^{8}$ Total fatty acid melting point $\left({ }^{\circ} \mathrm{C}\right)$.

this approach permitted not only the detection of hydroxy-FAME in the cyanopropyl siloxane capillary column, but also the identification of the position of the hydroxyl group by analysis of their mass spectra (Supplemental Figure S1; https://doi.org/10.3168/jds
.2017-13117). Other approaches have been reported for the analysis of hydroxy-FA in milk and dairy products. Marquez-Ruiz et al. (2011) described a method where oxygenated FAME from milk fat are analyzed after fractionation by solid-phase extraction silica cartridges fol-

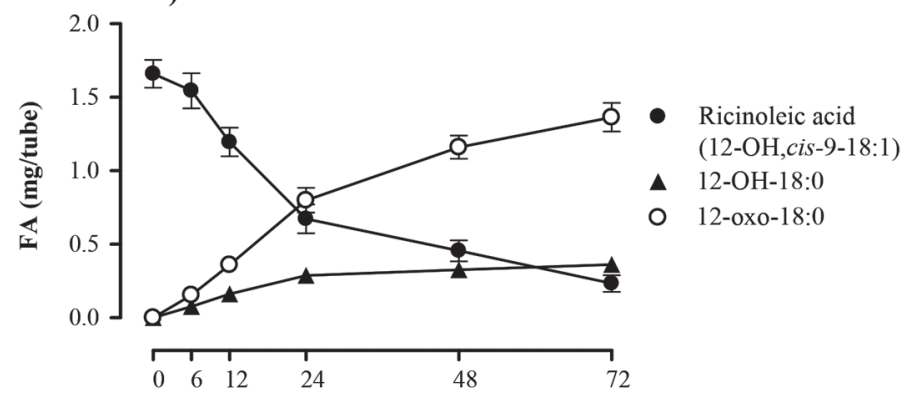

C)

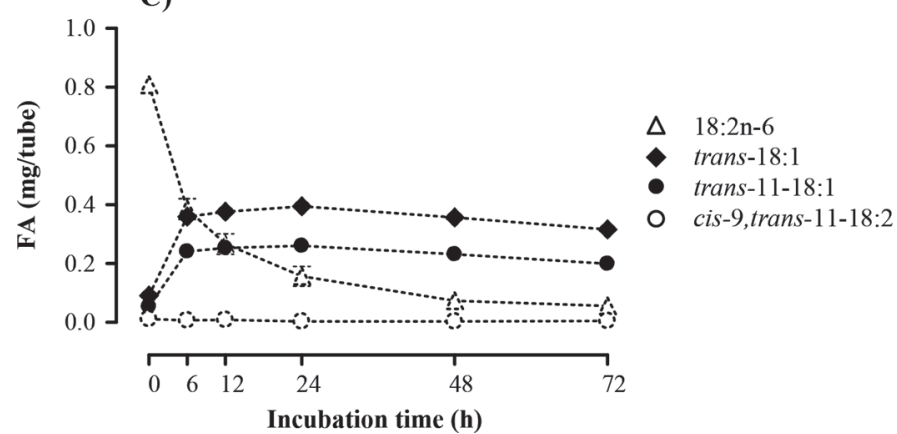

B)

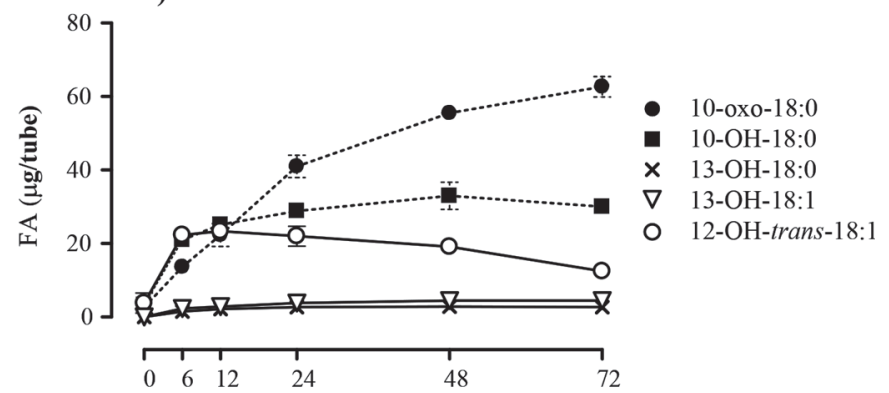

D)

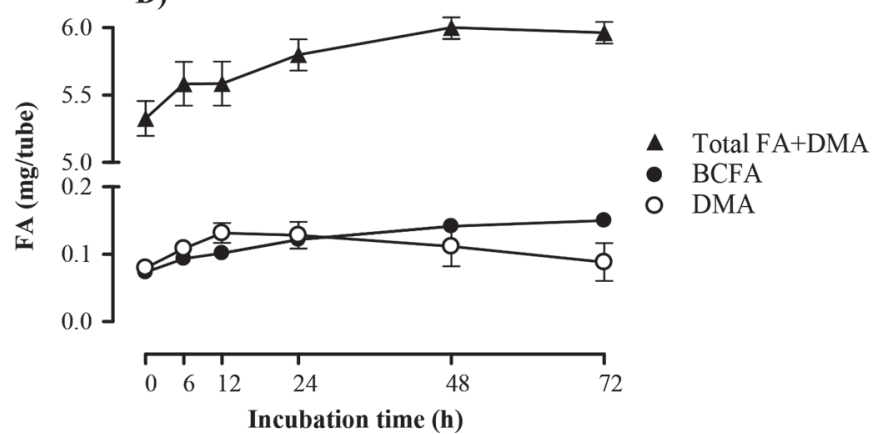

Figure 3. Influence of in vitro batch incubations of castor oil with strained rumen fluid during 0 to $72 \mathrm{~h}$, on (A) ricinoleic acid (12-OH, cis-9-18:1) and the major oxo- and hydroxy-fatty acids (FA); (B) minor oxo- and hydroxy-FA; (C) 18:2n-6 and biohydrogenation intermediates, trans-18:1, trans-11-18:1, and cis-9,trans-11-18:2; (D) total FA + dimethyl acetals (DMA), total branched-chain fatty acids (BCFA), and total DMA. 
Table 3. Effect of incubation time in C18 fatty acid composition $(\mu \mathrm{g} /$ tube) on 72 -h in vitro batch incubations with castor oil

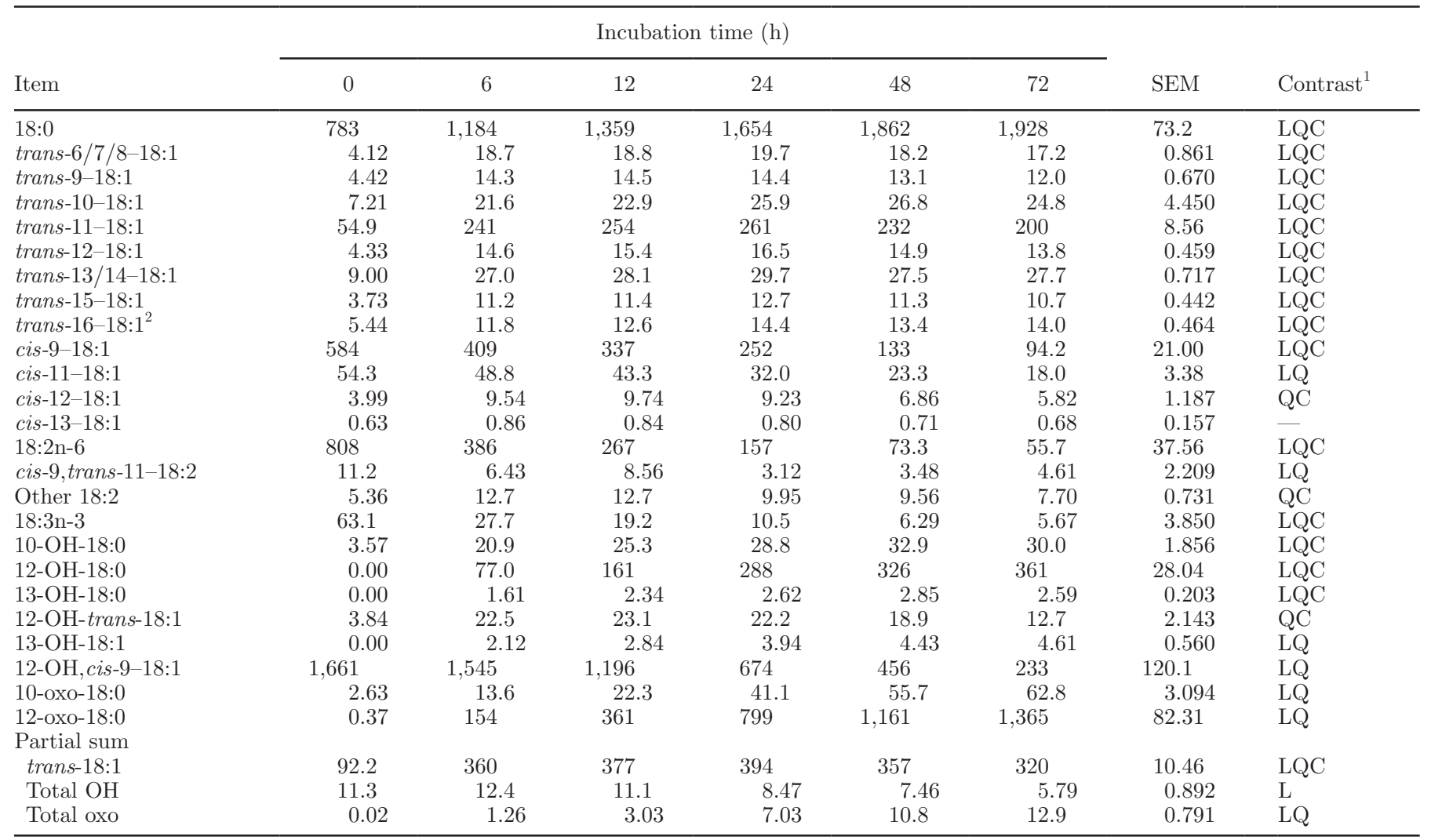

${ }^{1}$ Indicates significant $(P<0.05)$ linear $(\mathrm{L})$, quadratic $(\mathrm{Q})$, or cubic $(\mathrm{C})$ components of the response to incubation time.

${ }^{2}$ Contains cis-14-18:1 as minor component.

lowed by GLC using a medium polar capillary column. In other approach, lipids from milk fat samples were isolated by accelerated solvent extraction, then transesterified to obtain FAME, subsequently separated by solid-phase chromatography to obtain hydroxy-FAME, further converted into pentafluorobenzoyl derivatives, and analyzed by GLC with electron-capture negative ion mass spectrometry (Jenske and Vetter, 2008). These methods are more laborious and time consuming compared with our approach. Also, our method has the advantage that both hydroxy and non-hydroxy FA (e.g., the complex mixture of C18 FA) can be all separated and quantified in the same GLC chromatogram as illustrated in Figure 1.

Following this approach, we detected and identified 7 FA, together with ricinoleic acid, that were not detected in milk of the control group. These FA contained either a hydroxyl or an oxo (keto) group and composed about $7.7 \%$ of total FA in milk fat. Nevertheless, the ricinoleic acid was only found in minor amounts $(0.26 \%$ of total FA), which suggests that it was extensively metabolized in the rumen or tissues. This is consistent with the earlier studies of Robb et al. (1974) that identified trace amounts of hydroxy-FA in milk of dairy cows fed a diet containing $0.5 \%$ of castor meal and castor oil.

In addition, we identified the 10-OH-18:0 and 10-oxo18:0 in milk fat of both control and castor oil groups. These FA were already detected in ruminant milk (Halmemies-Beauchet-Filleau et al., 2011; Marquez-Ruiz et al., 2011) and were reported to derive from microbial hydration of $c i s-9-18: 1$ in the rumen to produce $10-\mathrm{OH}-$ 18:0, followed by oxidation to produce the 10-oxo-18:0 (Jenkins et al., 2006; McKain et al., 2010). Thus, it was not surprising that we also detected both FA in milk of both groups.

To the best of our knowledge, this is the first time that the 8-oxo-14:0, 8-OH-14:0, and 10-OH-16:0 are identified in milk fat. The 10-oxo-16:0 was previously detected in minor quantities in milk of dairy cows fed red-clover-based diets (Halmemies-Beauchet-Filleau et al., 2011). These authors suggested that the 10-oxo-16:0 could be formed from hydration and oxidation of cis9-16:1 in the rumen. Nevertheless, because we did not detect the 10-oxo-16:0 in milk of the control group, we 
Table 4. Effect of incubation time on dimethyl acetal (DMA) and fatty acid (FA) composition ( $\mu \mathrm{g} /$ tube), excluding C18 fatty acids, on 72 -h in vitro batch incubations with castor oil

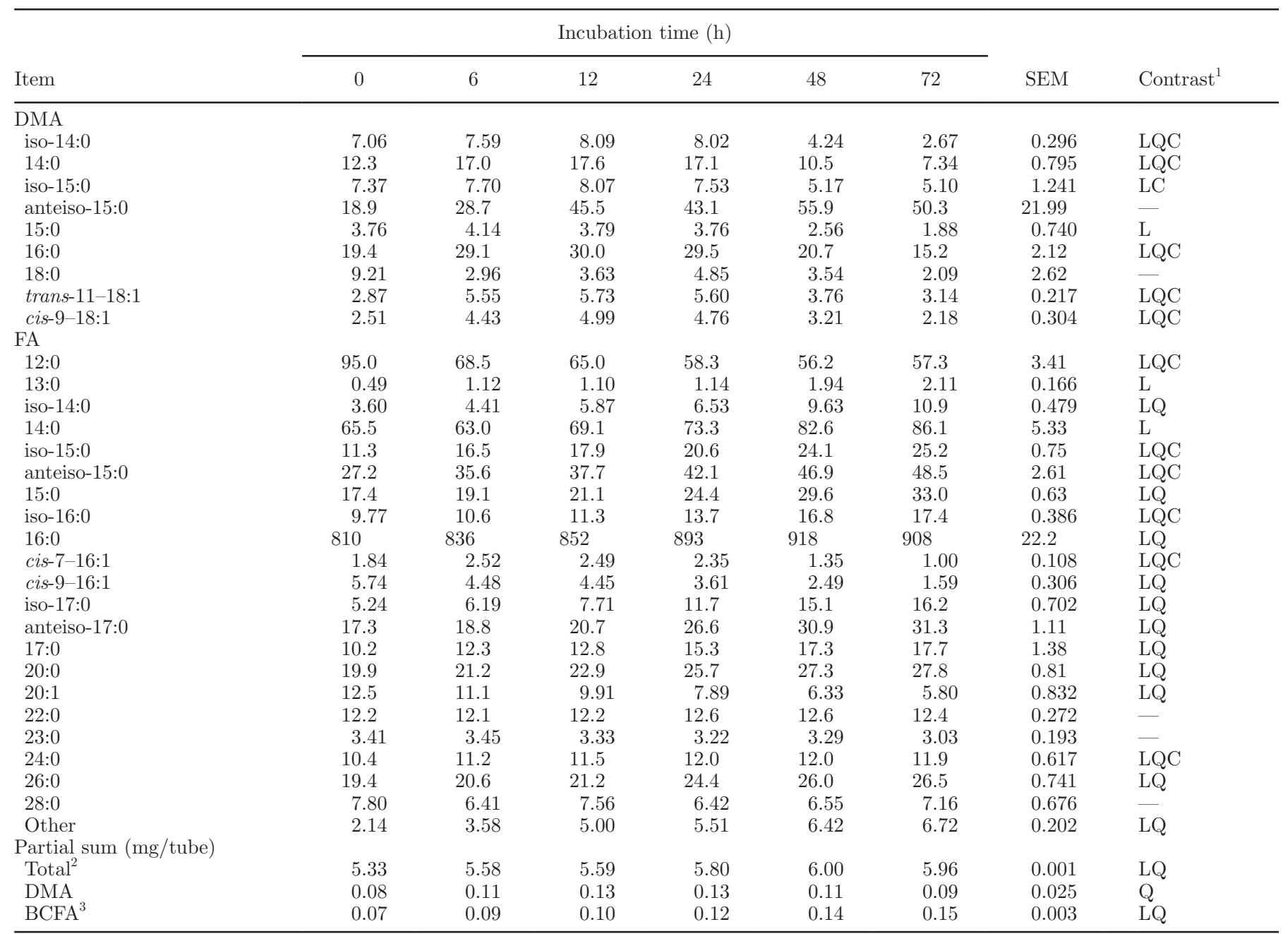

${ }^{1}$ Indicates significant $(P<0.05)$ linear $(\mathrm{L})$, quadratic $(\mathrm{Q})$, or cubic $(\mathrm{C})$ components of the response to incubation time.

${ }^{2}$ Includes the sum of DMA and FA.

${ }^{3}$ Branched-chain fatty acids, including all iso-FA and anteiso-FA.

suspect that in our study it derived from the ricinoleic acid metabolism, but it was not clear if it is formed in the rumen or in tissues.

We conducted in vitro batch incubations of castor oil with strained rumen fluid to explore if the oxygenated FA found in milk of the castor oil group were formed in the rumen. The dose of the castor oil $(40 \mathrm{~g} / \mathrm{kg}$ of DM) used on the in vitro experiments was chosen to maximize the range of products formed and to reproduce the in vivo conditions. The $72 \mathrm{~h}$ of incubation was chosen taking into account preliminary results in our laboratory, which revealed that ricinoleic acid is metabolized at a slow rate. Hence, our experiments showed that the 12-oxo-18:0 and 12-OH-18:0 were the main products formed during the $72 \mathrm{~h}$ of in vitro batch incubations with castor oil. Both 12-oxo-18:0 and 12-OH-18:0 increased as ricinoleic acid decreased, exceeding the quantity of ricinoleic acid after $24 \mathrm{~h}$ and $72 \mathrm{~h}$ of incubation, respectively (Figure 3A). Due the capacity of rumen bacteria to hydrogenate unsaturated double bonds and to oxidize hydroxy-FA (McKain et al., 2010), we suggest that the 12-OH-18:0 is formed by hydrogenation of cis-9 double bond of ricinoleic acid (12-OH,cis-9-18:1), followed by oxidation of the $\mathrm{OH}$ group to produce the 12-oxo-18:0. Indeed, Ramos Morales et al. (2012) reported that Butyrivibrio proteoclasticus, a known rumen bacteria, has the capacity to metabolize ricinoleic acid into 12-OH-18:0, but no other products were reported to be formed. However, we observed that 2 other hydroxy octadecenoic isomers (i.e., 12-OH-trans-18:1 
and 13-OH-18:1) and 3 oxygenated octadecanoic acids (i.e., 13-OH-18:0, 10-OH-18:0, and 10-oxo-18:0) also increased with incubation time (Figure 3B). From these FA, we believe that only the 12-OH-trans-18:1 could result from the metabolism of ricinoleic acid in the rumen, probably by isomerization of the cis-9 into a trans monoenoic hydroxy-FA, an isomer of ricinoleic acid. The trans configuration of 12-OH-trans-18:1 was putatively identified based on the fact that during the GLC analysis it elutes before the ricinoleic acid, similarly to the elution pattern of trans and cis 18:1 isomers. Moreover, its kinetic curve also supports the hypothesis of an initial cis/trans isomerization of ricinoleic acid, as 12-OH-trans-18:1 rapidly increased at first $12 \mathrm{~h}$ and then slowly decreased with time, most likely due to further hydrogenation. Nevertheless, as 12-OH-trans-18:1 is detected in small amounts, particularly when compared with 12-OH-18:0, the metabolization pathway involving an initial cis/trans isomerization might be of minor importance compared with the direct reduction of $c i s-9$ double bond.

The increased quantities of 10-oxo-18:0 and 10-OH18:1 with incubation time was expected because both FA are known to be formed by the microbial action on cis-9-18:1 as already discussed (Jenkins et al., 2006; McKain et al., 2010). In addition, we predicted that the formation of both 13-OH-18:1 and 13-OH-18:0 results from the rumen biohydrogenation of linoleic acid (18:2n6 ); indeed, it was already reported that rumen bacteria are capable of converting 18:2n-6 into 13-OH, cis-9-18:1 by hydration at position C12 (Hudson et al., 1998), and further hydrogenated, resulting in the formation of 13-OH-18:0. It would be expected to detect the final oxidation product (i.e., 13-oxo-18:0); however, it was

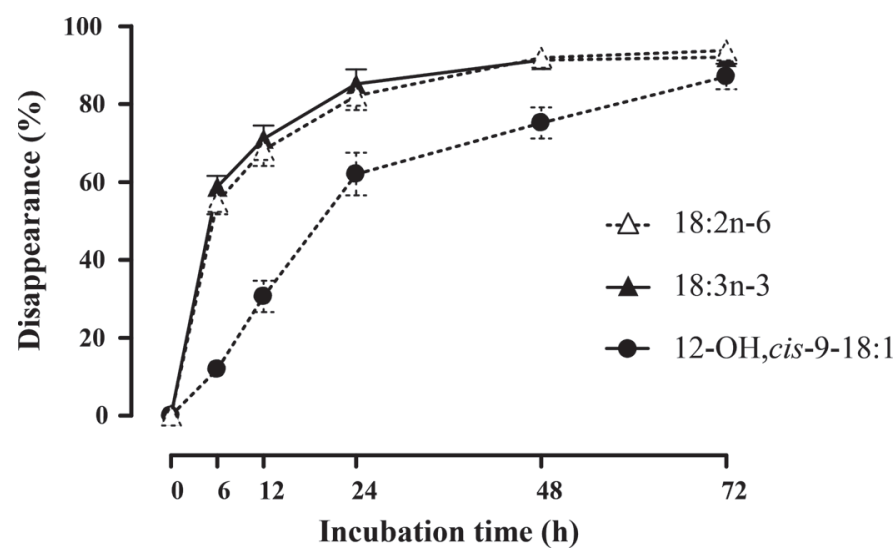

Figure 4. Disappearance (\%) of ricinoleic acid (12-OH, cis-9-18:1), linoleic acid (18:2n-6), and linolenic acid (18:3n-3) during 0 to $72 \mathrm{~h}$ of incubations of castor oil with strained rumen fluid. not possible to detect due to its low quantities and because it might co-elute with 12-oxo-18:0 in our chromatographic conditions.

A few studies explored the hypothesis that ricinoleic acid could be involved in the formation of rumenic acid (cis-9,trans-11-18:2) by rumen bacteria (Wallace et al., 2007; Ramos Morales et al., 2012) through mechanisms similar to that observed by lactic acid bacteria (Ogawa et al., 2005). However, neither Wallace et al. (2007) nor Ramos Morales et al. (2012) provided data to confirm that with rumen inocula. Consistent with these studies, we did not observe an increase in rumenic acid formation during the $72 \mathrm{~h}$ of in vitro batch incubations with castor oil. In contrast, the 18:2n-6 decreased with incubation time (Figure 3C); indeed, it is wellknown that $18: 2 \mathrm{n}-6$ is extensively biohydrogenated in the rumen. Consequently, the trans-18:1, in particular the trans-11-18:1, greatly increased in the first hours, confirming that $18: 2 \mathrm{n}-6$ is rapidly metabolized in the rumen. Additionally, we compute the percentages of disappearance of ricinoleic acid, as well as of 18:2n-6 and 18:3n-3 (the major substrates of ruminal biohydrogenation), and we verified that at $6 \mathrm{~h}$ of incubation time more than $50 \%$ of $18: 2 \mathrm{n}-6$ and $18: 3 \mathrm{n}-3$ disappear, whereas ricinoleic acid did not reach $20 \%$ of disappearance (Figure 4). Only at $72 \mathrm{~h}$ of incubation did the disappearance reach similar values. These results indicate that ricinoleic acid is metabolized at a considerable lower rate than both 18:2n-6 and 18:3n-3. Similar findings were reported by Wallace et al. (2007) during incubations of mixed rumen bacteria with ricinoleic acid. These differences are probably due to different enzyme activity rates (i.e., isomerases vs. reductases). Indeed, it is known that isomerization of $18: 2 \mathrm{n}-6$ and $18: 3 \mathrm{n}-3$ is very fast and that hydrogenation rates are slower (Troegeler-Meynadier et al., 2006). Our results suggest that the first step of the metabolism of ricinoleic acid by rumen bacteria involves reduction of the cis- 9 double bond rather than isomerization, so this might explain the slower disappearance rates of ricinoleic acid compared with 18:2n-6 and 18:3n-3. Despite the slow ricinoleic acid biohydrogenation rate, we found much lower concentrations of ricinoleic acid in milk than of its biohydrogenation derivatives. The reasons for that are not clear but might reflect differential absorption and transfer into the milk of ricinoleic acid and its derivatives. Moreover, biohydrogenation rate of ricinoleic acid might increase with adaptation of the ruminal microbial population to the presence of castor oil in diet.

Rumen microbial membranes contain plasmalogen lipids, which are a sub-class of phospholipids. Plasmalogens contains a long-chain FA attached at sn-2 position of glycerol and alk-1-enyl (vinyl) ether at the sn-1 
position, whereas the usual phospholipids contain a FA attached at both sn- 1 and sn-2 positions. During the $\mathrm{HCl} /$ methanol transesterification to prepare FAME, the DMA are also formed by cleavage of the vinyl ether chain of plasmalogenic lipids (Alves et al., 2013). Thus, the DMA composition, together with BCFA, might be used as rumen microbial internal markers. Castor oil, as the source of ricinoleic acid, does not seems to inhibit the growth and activity on rumen bacteria as the amount of total FA + DMA increased steadily with incubation time. Few studies reported that ricinoleic acid inhibited growth of specific rumen bacterial strains (Wallace et al., 2007; Ramos Morales et al., 2012). In our experiment the concentration of BCFA and DMA in the rumen showed different patterns with incubation time (Figure 3D). In the first hours, the amount of DMA was higher than the BCFA, but after $24 \mathrm{~h}$ of incubation an inversion occurred of the BCFA and DMA quantities, suggesting modifications on bacterial population or changes in the lipid composition of their cell membranes. Coincidentally, also at $24 \mathrm{~h}$ of incubation the 12-oxo-18:0 started to predominate over ricinoleic acid. It is tempting to hypothesize that alterations in the main oxygenated FA present in the incubation milieu are associated with shifts in bacterial population.

In summary, the detailed analysis of the products formed during in vitro batch incubations of castor oil with strained rumen fluid for $72 \mathrm{~h}$ showed that the 12-oxo-18:0, 12-OH-18:0, and 12-OH-trans-18:1 derived from the metabolism of ricinoleic in the rumen. Thus, the 8-OH-14:0, 10-OH-16:0, 8-oxo-14:0, and 10-oxo-16:0 that we found in milk fat of goats fed ricinoleic acid are most likely formed in tissues after absorption of the metabolites generated in the rumen. Other oxygenated FA with less than 18 carbons, as the 8-oxo-16:0 and 8-OH-16:0, were found in ruminant milk fat (Halmemies-Beauchet-Filleau et al., 2011; Marquez-Ruiz et al., 2011). These authors suggested that both FA originated from partial $\beta$-oxidation of 10-oxo-18:0 and 10$\mathrm{OH}-18: 0$ in tissues, respectively. Fatty acid $\beta$-oxidation is a multistep process by which FA are broken down close to the carboxyl group, producing FA with 2 carbons shorter than the original. Thus, we anticipate that the 10-OH-16:0 and 8-OH-14:0 found in goats milk are successive products of $\beta$-oxidation of $12-\mathrm{OH}-18: 0$, and the 10-oxo-16:0 and 8-oxo-14:0 are successive products of $\beta$-oxidation of 12-oxo-18:0 in tissues. In Figure 5 we summarize the proposed metabolism of ricinoleic in dairy ruminants. Briefly, it is hydrogenated in the rumen forming the 12-OH-18:0, which is further oxidized to produce the 12-oxo-18:0 as the main product. Both oxygenated FA escape the rumen and are further absorbed and accessible in tissues to partial $\beta$-oxidation, producing oxo- and hydroxy-FA that are 2 (10-oxo16:0 and 10-OH-16:0) or 4 (8-oxo-14:0 and 8-OH-14:0) carbons shorter. Nevertheless, only a minor quantity of 12-oxo-18:0 and 12-OH-18:0 are oxidized in tissues and both FA are excreted in milk together with minor quantities of $\beta$-oxidation FA products.

It is well known that milk FA composition is greatly influenced by feeding factors, particularly by the addition of vegetable oils to the rations (Kliem and Shingfield, 2016). It has been proposed that the ability to maintain milk fat melting point within physiological values could play a role in the regulation of milk fat secretion when milk FA composition varies (Toral et al., 2013). However, our data indicate that this regulatory mechanism might be surpassed as the inclusion of castor oil in goat diets clearly increased the estimated milk melting point compared with control. Nevertheless, total FA milk melting points of both control and castor oil groups are within the range of $36.4^{\circ} \mathrm{C} \pm$ 7.28 (mean \pm SD) found by Toral et al. (2013), which were calculated from 278 milk FA profiles from 3 dairy ruminant species and different dietary treatments. The increased melting point was probably due to the highest proportion of 12-oxo-18:0 in milk fat (4.9\% of total FA) of the castor oil group, considering that the melting point of synthetic 12-oxo-18:0 averages $80^{\circ} \mathrm{C}$ (Grummitt and Siedschlag, 1949). The reduction in the proportion of SFA (44.8 to $48.6 \%$ of total FA) in milk of the castor oil group compared with the control did not seem to compensate for the high melting point of the oxygenated FA metabolites formed from ricinoleic acid. The high milk melting point estimated for the castor oil group might have technological implications in the derived dairy products, although these aspects were not evaluated in this study. However, previous studies showed that inclusion of castor oil in dairy goat diets had no effect on the physicochemical composition, rheological parameters, or sensory quality of cheese (Lacerda de Medeiros et al., 2013).

In our experiment, the incorporation of castor oil in goat diets did not negatively affect the nutritional quality of milk fat. Indeed, the proportion of total SFA decreased in milk of the castor oil group compared with the control; this decrease was mostly due to the reduction of 18:0, whereas the 14:0 and 16:0 that are the SFA associated with incidence of cardiovascular disease (FAO, 2003) did not differ from the control. Moreover, inclusion of castor oil in diet did not increase the proportion of trans $\mathrm{FA}$ in milk in contrast with the incorporation of other vegetal oils (Kliem and Shingfield, 2016). Nevertheless, the proportion of the 18:2n-6 decreased and the cis-9-18:1 tended to decrease in milk of the castor oil group compared with the con- 


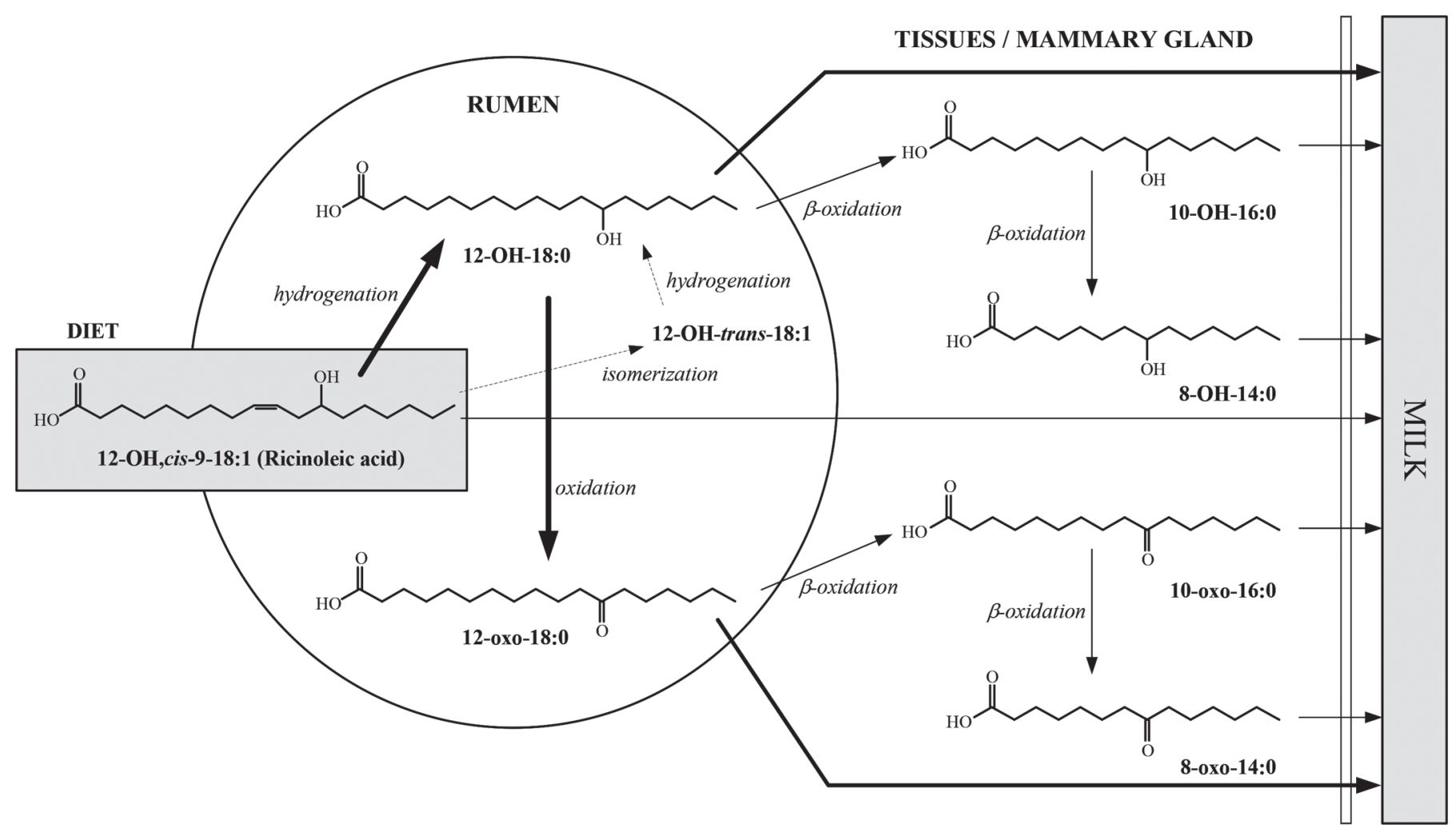

Figure 5. Proposed metabolism of ricinoleic acid (12-OH,cis-9-18:1) in dairy ruminants. Thick arrows represent the main metabolic pathways and thin arrows the putative pathways including all the oxo-fatty acids (FA) and hydroxy-FA detected in milk fat of goats fed castor oil, whereas the dashed arrows represent putative pathways including the hydroxy-FA detected in incubations of castor oil with strained rumen fluid.

trol, but this was compensated for by the increase of oxo- and hydroxy-FA, which may have some health benefits to humans. Indeed, ricinoleic acid is known for its anti-inflammatory and analgesic properties (Boddu et al., 2015), whereas hydroxystearic isomers have been reported to exert strong antiproliferative effects in human adenocarcinoma and osteosarcoma cell lines (Pagnotta et al., 2006; Calonghi et al., 2007; Parolin et al., 2012). However, more studies are needed to determine the health effects of these oxygenated FA to consumers.

\section{CONCLUSIONS}

Our results on the metabolism of ricinoleic acid in ruminants show that the microbial activity in the rumen metabolizes ricinoleic acid (12-OH, cis-9-18:1) to produce $12-\mathrm{OH}-18: 0$, followed by oxidation to produce 12-oxo-18:0 as the main product. Both FA seem to flow to the abomasum, absorbed and further metabolized through partial $\beta$-oxidation forming oxo- and hydroxyFA 2 or 4 carbons shorter than the initial 12-oxo-18:0 and 12-OH-18:0, respectively. Finally, large quantities of these 2 rumen-FA are excreted in milk together with minor quantities of ricinoleic acid and the FA resulting from the $\beta$-oxidation. Overall, the incorporation of castor oil in goat diets led to the accumulation of the oxygenated FA in milk, which may have some beneficial health implications for consumers.

\section{ACKNOWLEDGMENTS}

The authors gratefully acknowledge the Fundação para a Ciência e a Tecnologia (FCT, Lisboa, Portugal) and Conselho Nacional de Desenvolvimento Científico e Tecnológico (CNPq, Brasília, Brazil; Process 490554/2013-0) for financial support. The work was also supported by FCT through the grant to SPA (SFRH/BPD/76836/2011) and research project UID/ CVT/00276/2013.

\section{REFERENCES}

Alves, S. P., J. Santos-Silva, A. R. J. Cabrita, A. J. M. Fonseca, and R. J. B. Bessa. 2013. Detailed dimethylacetal and fatty acid composition of rumen content from lambs fed lucerne or concentrate supplemented with soybean oil. PLoS One 8:e58386. https://doi .org/10.1371/journal.pone.0058386. 
Binder, R. G., T. H. Applewhite, G. O. Kohler, and L. A. Goldblatt. 1962. Chromatographie analysis of seed oils. Fatty acid composition of castor oil. J. Am. Oil Chem. Soc. 39:513-517. https://doi .org/10.1007/bf02672540.

Boddu, S. H. S., H. Alsaab, S. Umar, S. P. Bonam, H. Gupta, and S. Ahmed. 2015. Anti-inflammatory effects of a novel ricinoleic acid poloxamer gel system for transdermal delivery. Int. J. Pharm. 479:207-211. https://doi.org/10.1016/j.ijpharm.2014.12.051.

Calonghi, N., E. Pagnotta, C. Parolin, C. Molinari, C. Boga, F. Dal Piaz, G. L. Brusa, M. A. Santucci, and L. Masotti. 2007. Modulation of apoptotic signalling by 9-hydroxystearic acid in osteosarcoma cells. BBA Mol. Cell. Biol. Lipids 2882:139-146. https://doi .org/10.1016/j.bbalip.2006.11.012.

Christie, W. W., and X. Han. 2012. Chapter 7-Preparation of derivatives of fatty acids. Pages 145-158 in Lipid Analysis. 4th ed. Woodhead Publishing Limited, Cambridge, UK.

Cruz, O. T. B., M. V. Valero, F. Zawadzki, D. C. Rivaroli, R. M. do Prado, B. S. Lima, and I. N. do Prado. 2014. Effect of glycerine and essential oils (Anacardium occidentale and Ricinus communis) on animal performance, feed efficiency and carcass characteristics of crossbred bulls finished in a feedlot system. Ital. J. Anim. Sci. 13:3492. https://doi.org/10.4081/ijas.2014.3492.

de Jesus, E. F., T. A. Del Valle, G. D. Calomeni, T. H. Silva, C. S. Takiya, T. H. A. Vendramini, P. G. Paiva, G. G. Silva, A. S. Netto, and F. P. Renno. 2016. Influence of a blend of functional oils or monensin on nutrient intake and digestibility, ruminal fermentation and milk production of dairy cows. Anim. Feed Sci. Technol. 219:59-67. https://doi.org/10.1016/j.anifeedsci.2016.06.003.

Eglinton, G., D. H. Hunneman, and A. McCormick. 1968. Gas chromatographic - mass spectrometric studies of long chain hydroxy acids.-III.1 The mass spectra of the methyl esters trimethylsilyl ethers of aliphatic hydroxy acids. A facile method of double bond location. J. Mass Spectrom. 1:593-611. https://doi.org/10.1002/ oms.1210010413.

FAO. 2003. Food and Agriculture Organization of the United Nations. World Agriculture: Towards 2015/2030: An FAO Perspective. Earthscan, UK.

Gandra, J. R., P. C. Nunes Gil, N. R. B. Consolo, E. R. S. Gandra, and A. A. O. Gobesso. 2012. Addition of increasing doses of ricinoleic acid from castor oil (Ricinus communis L.) in diets of Nellore steers in feedlots. J. Anim. Feed Sci. 21:566-576.

Gandra, J. R., P. C. Nunes Gil, E. R. S. Gandra, T. A. d. Vale, R. V. Barletta, F. Zanferari, E. Ferreira de Jesus, C. S. Takiya, R. D. Mingoti, G. F. Almeida, P. G. Paiva, and A. A. O. Gobesso. 2014. Productive performance of Simmental dairy cows supplemented with ricinoleic acid from castor oil. Arch. Zootec. 63:575-585.

Goering, H. K., and P. J. Van Soest. 1970. Forage fiber analyses (Apparatus, reagents, procedures, and some applications). Agric. Handbook No. 379. ARS-USDA. Washington, DC.

Grummitt, O., and K. G. Siedschlag. 1949. The synthesis of 12-ketostearic acid. J. Am. Oil Chem. Soc. 26:690-691. https://doi.org/ 10.1007/Bf02903173.

Halmemies-Beauchet-Filleau, A., T. Kokkonen, A. M. Lampi, V. Toivonen, K. J. Shingfield, and A. Vanhatalo. 2011. Effect of plant oils and camelina expeller on milk fatty acid composition in lactating cows fed diets based on red clover silage. J. Dairy Sci. 94:44134430. https://doi.org/10.3168/jds.2010-3885.

Hudson, J. A., B. Morvan, and K. N. Joblin. 1998. Hydration of linoleic acid by bacteria isolated from ruminants. FEMS Microbiol. Lett. 169:277-282. https://doi.org/10.1111/j.1574-6968.1998.tb13329.x.

Jenkins, T. C., A. A. AbuGhazaleh, S. Freeman, and E. J. Thies. 2006. The production of 10-hydroxystearic and 10-ketostearic acids is an alternative route of oleic acid transformation by the ruminal microbiota in cattle. J. Nutr. 136:926-931.

Jenske, R., and W. Vetter. 2008. Gas chromatography/electron-capture negative ion mass spectrometry for the quantitative determination of 2-and 3-hydroxy fatty acids in bovine milk fat. J. Agric. Food Chem. 56:5500-5505. https://doi.org/10.1021/jf800647w.

Kliem, K. E., and K. J. Shingfield. 2016. Manipulation of milk fatty acid composition in lactating cows: Opportunities and challeng- es. Eur. J. Lipid Sci. Technol. 118:1661-1683. https://doi.org/10 .1002/ejlt.201400543.

Lacerda de Medeiros, E. J., R. C. Ramos do Egypto Queiroga, A. N. de Medeiros, M. A. Delmondes Bomfim, A. S. Malveira Batista, S. S. dos Santos Felex, and M. S. Madruga. 2013. Sensory profile and physicochemical parameters of cheese from dairy goats fed vegetable oils in the semiarid region of Brazil. Small Rumin. Res. 113:211-218. https://doi.org/10.1016/j.smallrumres.2013.02.006.

Maia, M. O., I. Susin, E. M. Ferreira, C. P. Nolli, R. S. Gentil, A. V. Pires, and G. B. Mourao. 2012a. Intake, nutrient apparent digestibility and ruminal constituents of sheep fed diets with canola, sunflower or castor oils. Rev. Bras. Zootec. 41:2350-2356.

Maia, M. O., I. Susin, A. V. Pires, R. S. Gentil, E. M. Ferreira, C. Q. Mendes, and S. M. de Alencar. 2012b. Growth, carcass characteristics, chemical composition and fatty acid profile of the longissimus dorsi muscle in goat kids fed diets with castor oil. Rev. Bras. Zootec. 41:2343-2349.

Marquez-Ruiz, G., V. Rodriguez-Pino, and M. A. de la Fuente. 2011. Determination of 10-hydroxystearic, 10-ketostearic, 8-hydroxypalmitic, and 8-ketopalmitic acids in milk fat by solid-phase extraction plus gas chromatography-mass spectrometry. J. Dairy Sci. 94:4810-4819. https://doi.org/10.3168/jds.2011-4424.

McKain, N., K. J. Shingfield, and R. J. Wallace. 2010. Metabolism of conjugated linoleic acids and 18: 1 fatty acids by ruminal bacteria: Products and mechanisms. Microbiology 156:579-588. https://doi .org/10.1099/mic.0.036442-0.

Medeiros, E., R. Queiroga, M. Oliveira, A. Medeiros, M. Sabedot, M. Bomfim, and M. Madruga. 2014. Fatty acid Profile of cheese from dairy goats fed a diet enriched with castor, sesame and faveleira vegetable oils. Molecules 19:992-1003. https://doi.org/10.3390/ molecules19010992

Novak, A. F., G. C. Clark, and H. P. Dupuy. 1961. Antimicrobial activity of some ricinoleic and oleic acid derivatives. J. Am. Oil Chem. Soc. 38:321-324. https://doi.org/10.1007/bf02638439.

NRC. 2007. Nutrient Requirements of Small Ruminants: Sheep, Goats, Cervids, and New World Camelids. Natl. Acad. Press, Washington, DC.

Ogawa, J., S. Kishino, A. Ando, S. Sugimoto, K. Mihara, and S. Shimizu. 2005. Production of conjugated fatty acids by lactic acid bacteria. J. Biosci. Bioeng. 100:355-364. https://doi.org/10.1263/ jbb.100.355.

Pagnotta, E., N. Calonghi, C. Boga, and L. Masotti. 2006. N-methylformamide and 9-hydroxystearic acid: two anti-proliferative and differentiating agents with different modes of action in colon cancer cells. Anticancer Drugs 17:521-526. https://doi.org/10.1097/ 00001813-200606000-00005.

Parolin, C., N. Calonghi, E. Presta, C. Boga, P. Caruana, M. Naldi, V. Andrisano, L. Masotti, and G. Sartor. 2012. Mechanism and stereoselectivity of HDAC I inhibition by (R)-9-hydroxystearic acid in colon cancer. BBA Mol. Cell. Biol. Lipids 1821:1334-1340. https://doi.org/10.1016/j.bbalip.2012.07.007.

Pereira, R. A. G., C. J. B. Oliveira, A. N. Medeiros, R. G. Costa, M. A. D. Bomfim, and R. C. R. E. Queiroga. 2010. Physicochemical and sensory characteristics of milk from goats supplemented with castor or licuri oil. J. Dairy Sci. 93:456-462. https://doi.org/10 .3168/jds.2009-2315.

Prado, I. N., O. T. B. Cruz, M. V. Valero, F. Zawadzki, C. E. Eiras, D. C. Rivaroli, R. M. Prado, and J. V. Visentainer. 2016. Effects of glycerin and essential oils (Anacardium occidentale and Ricinus communis) on the meat quality of crossbred bulls finished in a feedlot. Anim. Prod. Sci. 56:2105-2114. https://doi.org/10.1071/ an14661.

Ramos Morales, E., M. A. Mata Espinosa, N. McKain, and R. J. Wallace. 2012. Ricinoleic acid inhibits methanogenesis and fatty acid biohydrogenation in ruminal digesta from sheep and in bacterial cultures. J. Anim. Sci. 90:4943-4950. https://doi.org/10.2527/jas .2011-4670.

Rego, O. A., S. P. Alves, L. M. S. Antunes, H. J. D. Rosa, C. M. M. Alfaia, J. A. M. Prates, A. R. J. Cabrita, A. J. M. Fonseca, and R. J. B. Bessa. 2009. Rumen biohydrogenation-derived fatty acids 
in milk fat from grazing dairy cows supplemented with rapeseed, sunflower, or linseed oils. J. Dairy Sci. 92:4530-4540. https://doi .org/10.3168/jds.2009-2060.

Robb, J. G., R. C. Laben, H. G. Walker Jr., and V. Herring. 1974 Castor meal in dairy rations. J. Dairy Sci. 57:443-450. https://doi .org/10.3168/jds.S0022-0302(74)84912-X.

Silva, L. G. d., J. A. Torrecilhas, M. G. Ornaghi, C. E. Eiras, R. M. d. Prado, and I. N. d. Prado. 2014. Glycerin and essential oils in the diet of Nellore bulls finished in feedlot: Animal performance and apparent digestibility. Acta Sci. Anim. Sci. 36:177-184. https://doi .org/10.4025/actascianimsci.v36i2.23089.

Toral, P. G., L. Bernard, Y. Chilliard, and F. Glasser. 2013. Short communication: Diet-induced variations in milk fatty acid composition have minor effects on the estimated melting point of milk fat in cows, goats, and ewes: Insights from a meta-analysis. J. Dairy Sci. 96:1232-1236. https://doi.org/10.3168/jds.2012-6046.
Troegeler-Meynadier, A., L. Bret-Bennis, and F. Enjalbert. 2006. Rates and efficiencies of reactions of ruminal biohydrogenation of linoleic acid according to $\mathrm{pH}$ and polyunsaturated fatty acids concentrations. Reprod. Nutr. Dev. 46:713-724. https://doi.org/ 10.1051/rnd:2006046.

Valero, M. V., J. A. Torrecilhas, F. Zawadzki, E. G. Bonafe, G. S. Madrona, R. M. do Prado, R. A. Cortez Passetti, D. C. Rivaroli, J. V. Visentainer, and I. N. do Prado. 2014. Propolis or cashew and castor oils effects on composition of Longissimus muscle of crossbred bulls finished in feedlot. Chil. J. Agric. Res. 74:445-451. https://doi.org/10.4067/s0718-58392014000400011.

Wallace, R. J., N. McKain, K. J. Shingfield, and E. Devillard. 2007. Isomers of conjugated linoleic acids are synthesized via different mechanisms in ruminal digesta and bacteria. J. Lipid Res. 48:2247-2254. https://doi.org/10.1194/jlr.M700271-JLR200. 